\title{
Apolipoprotein E $\varepsilon 4$ Allele Is Unrelated to Cognitive or Functional Decline in Alzheimer's Disease: Retrospective and Prospective Analysis
}

\author{
Timothy Kleiman $^{\mathrm{a}}$ Kristina Zdanys $^{\mathrm{a}}$ Benjamin Black ${ }^{\mathrm{a}}$ Tracy Rightmer ${ }^{\mathrm{a}}$ \\ Monique Grey $^{\mathrm{a}}$ Katherine Garman ${ }^{\mathrm{a}}$ Martha MacAvoy ${ }^{\mathrm{a}}$ Joel Gelernter ${ }^{\mathrm{b}}$ \\ Christopher van Dyck ${ }^{\mathrm{a}, \mathrm{c}}$
}

${ }^{a}$ Alzheimer's Disease Research Unit; ${ }^{b}$ Division of Molecular Psychiatry, Department of Psychiatry, and

'Department of Neurobiology, Yale University School of Medicine, New Haven, Conn., USA

\section{Key Words}

Alzheimer's disease • Apolipoprotein E · Cognition •

Activities of daily living

\begin{abstract}
Objective: The apolipoprotein $\mathrm{E}(\mathrm{ApoE}) \varepsilon 4$ allele is a welldocumented genetic risk factor for Alzheimer's disease (AD). Its role, if any, in the progression of cognitive and functional impairment in AD has been the subject of discrepant reports in the literature. This study aimed to determine whether ApoE $\varepsilon 4$ dose is related to the progression of cognitive and functional decline in AD patients by combined retrospective and prospective analyses. Methods: A sample of 366 AD patients was genotyped for ApoE. Subjects received tests of cognition (Mini-Mental State Examination, MMSE; Alzheimer's Disease Assessment Scale-Cognitive subscale, ADASCog) and daily function (Instrumental Activities of Daily Living, IADL; Alzheimer's Disease Cooperative Study-Activities of Daily Living, ADCS-ADL) at baseline and at multiple subsequent time points during their participation in a variety of research protocols. In retrospective analyses, scores on baseline cognitive and functional measures were compared cross-sectionally among genotype groups, controlling for duration of symptoms. In prospective analyses, longitudinal
\end{abstract}

rates of change for each measure were computed by linear regression and compared across genotype groups. Results: No association was observed between ApoE $\varepsilon 4$ dose and any of the retrospective or prospective measures of cognitive or functional decline in this AD patient sample. Conclusions: Although ApoE $\varepsilon 4$ increases the risk for AD and decreases the age of disease onset in population studies, it did not significantly influence the rate of disease progression in cognitive or functional domains in our sample.

Copyright $\odot 2006$ S. Karger AG, Basel

\section{Introduction}

The apolipoprotein E (ApoE) locus on chromosome 19 is the only well-documented genetic risk factor for the development of sporadic AD [1]. Among the three major isoforms of ApoE, the most common allele is $\varepsilon 3$, which occurs with approximately $78 \%$ frequency in populations of European ancestry, followed by $\varepsilon 4$ at $14 \%$, and $\varepsilon 2$ at $8 \%$ $[2,3]$. In a variety of cross-cultural studies, ApoE $\varepsilon 4$ has been reported to increase an individual's risk of developing $\mathrm{AD}$, and decrease an individual's age of onset, in proportion to the number of $\varepsilon 4$ alleles present $[4,5]$. By contrast, the ApoE $\varepsilon 2$ allele has been reported to have a 'pro-

\section{KARGER}

Fax +4161306 1234 E-Mail karger@karger.ch www.karger.com

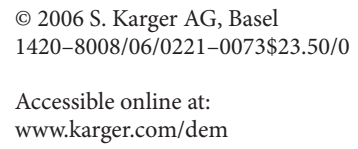

Christopher H. van Dyck, MD

Alzheimer's Disease Research Unit

Department of Psychiatry, Yale University School of Medicine

One Church Street, Suite 600, New Haven, CT 06510 (USA)

Tel. +1 203764 8100, Fax +1 203764 8111, E-Mail christopher.vandyck@yale.edu 
tective' effect, decreasing the risk of developing $\mathrm{AD}$ and delaying the age of onset [6].

Besides increasing $\mathrm{AD}$ risk and accelerating $\mathrm{AD}$ onset, the ApoE $\varepsilon 4$ allele has also been shown to promote the neuropathological features of $\mathrm{AD}$, including $\beta$-amyloid (Aß) deposition [7-10] and neurofibrillary tangle formation [7-10]. Furthermore, the $\varepsilon 4$ allele appears to be associated with the clinical manifestations of $\mathrm{AD}$ through an association with its pathological hallmarks rather than another mechanism [11]. The role of ApoE in the central nervous system and the mechanism by which the $\varepsilon 4$ allele confers an increased risk of AD remain largely unspecified [for a review, see 12]. Proposed mechanisms for the involvement of ApoE in AD pathogenesis include differential properties of ApoE isoforms with respect to cholesterol homeostasis [13], binding to $A \beta[14,15]$, or binding to the microtubule-associated proteins MAP2c and tau [16].

The links between the ApoE $\varepsilon 4$ allele and decreased age of $\mathrm{AD}$ onset and increased accumulation of pathological features has prompted the hypothesis that $\varepsilon 4$ may play a role in accelerating the clinical manifestations of the disease. However, that hypothesis has thus far not been confirmed by most clinical studies. The majority of studies have shown no effect of ApoE genotype on rate of cognitive decline in $\mathrm{AD}[8,17-29]$. However, some investigators have reported that the presence of at least one $\varepsilon 4$ allele may increase [30-32] or even decrease $[33,34]$ the rate of cognitive decline.

Despite widespread interest in the potential role of ApoE in modulating the course of cognitive symptoms in $\mathrm{AD}$, comparatively few studies have addressed the possibility that ApoE may influence the rate of functional decline in activities of daily living (ADLs) experienced by $\mathrm{AD}$ patients. Loss of performance in ADLs, such as selfcare, grooming and common household tasks, is associated with increased patient and caregiver distress, and greater healthcare costs $[35,36]$. Although ADL performance is associated with global cognitive status in $\mathrm{AD}$, recent studies have demonstrated a more specific correlation of ADL impairment with executive cognitive dysfunction and frontally mediated behavioral disturbances $[37,38]$. This evidence suggests the importance of monitoring ADL performance directly, rather than via broad cognitive tests like the MMSE [37]. The few genetic studies that have used ADL performance as an outcome variable have thus far found no significant effect of ApoE genotype on functional decline in $\operatorname{AD}[8,19,22,28]$.

Almost all previous studies of ApoE $\varepsilon 4$ effects on $\mathrm{AD}$ progression have used prospective longitudinal measurement, although one prior report [33] employed a cross- sectional retrospective analysis, while controlling for disease duration. Prospective analyses permit the empiric measurement of cognitive and functional outcomes in patients followed over time. While retrospective designs introduce the error inherent in estimating duration of symptoms, they allow examination of a longer segment of the disease course, including the earliest stages. Thus, studies that simultaneously utilize both methodologies in the same cohort of patients may provide a unique perspective for this growing literature. The aims of our study were to combine retrospective and prospective analyses: to help resolve the ambiguity of the literature regarding ApoE genotype and cognitive decline, and to provide novel data relating ApoE genotype to widely used measures of $\mathrm{ADL}$ performance.

\section{Methods}

Subjects

The study sample comprised 366 patients with probable AD [39] who enrolled in a study of the genetics of $\mathrm{AD}$ and were initially evaluated in the Yale Alzheimer's Disease Research Unit between July 1992 and August 2003. Most of these patients then participated in a variety of other research protocols permitting the accumulation of longitudinal cognitive and functional data. Thirteen of these patients have subsequently died and had autopsy confirming definite $\mathrm{AD}$ [40]. The demographics and clinical characteristics of patients are displayed in table 1 . The racial composition of the sample was: European-American $(\mathrm{n}=354$; 96.7\%), AfricanAmerican $(n=6 ; 1.6 \%)$, Hispanic $(n=5 ; 1.4 \%)$ and Asian-American $(\mathrm{n}=1 ; 0.3 \%)$.

All patients underwent a comprehensive evaluation by a research physician and ancillary staff, including cognitive assessment, medical history, physical and neurological examinations, serum chemistries, thyroid function studies, complete blood count, $\mathrm{B}_{12}$, folate, VDRL, urinalysis, electrocardiogram, and brain MRI or CT. Subjects were excluded for any neurological or medical disorder (other than AD) that could produce cognitive deterioration or for significant psychiatric illness, alcohol, or substance abuse. Research protocols in which subjects participated following their initial evaluation included investigational therapeutic trials, neuroimaging studies, and neuropsychological studies. Some investigational and clinically prescribed $\mathrm{AD}$ treatments received by subjects - in particular cholinesterase inhibitors, high-dose vitamin $\mathrm{E}$ ( $\geq 400$ IU daily), and psychotropic drugs - may potentially have impacted cognitive and functional variables analyzed in this study. These treatments were assumed to be independently distributed with regard to ApoE genotype; however, this assumption was also tested statistically (see below).

Family history of AD was assessed using the Alzheimer Dementia Risk Questionnaire [41] and the Dementia Questionnaire [42] and was considered to be positive if at least one first-degree relative met criteria for primary degenerative dementia. No cases suggestive of autosomal dominant transmission were identified. Additionally, each subject was evaluated for an approximate date of dis- 
Table 1. Subject characteristics (mean \pm $\mathrm{SD})$

\begin{tabular}{llll}
\hline & $\begin{array}{c}\varepsilon 4 \text { non-carriers } \\
(\mathrm{n}=156)\end{array}$ & $\begin{array}{l}\varepsilon 4 \text { heterozygotes } \\
(\mathrm{n}=159)\end{array}$ & $\begin{array}{l}\varepsilon 4 \text { homozygotes } \\
(\mathrm{n}=51)\end{array}$ \\
\hline Demographics & & & \\
$\quad$ Age & $73.4 \pm 9.6$ & $74.4 \pm 7.3$ & $71.6 \pm 7.0$ \\
$\quad$ Sex, female & $59.6 \%$ & $59.1 \%$ & $70.6 \%$ \\
$\quad$ Education, years & $13.1 \pm 3.3$ & $13.7 \pm 3.5$ & $13.6 \pm 2.8$ \\
Disease characteristics & & & \\
$\quad$ Onset age & $69.0 \pm 9.5$ & $69.9 \pm 7.3$ & $67.0 \pm 6.8$ \\
$\quad$ Duration, years & $4.5 \pm 2.0$ & $4.5 \pm 2.1$ & $4.6 \pm 1.9$ \\
$\quad$ Family history, positive & $42.9 \%$ & $52.8 \%$ & $54.9 \%$ \\
$\quad$ ApoE genotype & $152,3141_{3,3}$ & $52,4154,4$ & 514,4 \\
Concomitant therapies at baseline & & & $29.4 \%$ \\
$\quad$ Cholinesterase inhibitors & $37.8 \%$ & $36.5 \%$ & $0.0 \%$ \\
$\quad$ Antipsychotics & $3.2 \%$ & $4.4 \%$ & $19.6 \%$ \\
Antidepressants & $14.7 \%$ & $20.1 \%$ & $39.2 \%$ \\
$\quad$ Vitamin E (400 IU daily) & $35.9 \%$ & $36.5 \%$ & \\
\hline
\end{tabular}

Family history was positive if primary degenerative dementia was present in a first-degree relative. ease onset, based on careful review of medical records and detailed interviews with one or more primary caregivers. The date of onset was operationally defined as the date at which the 'earliest definite symptom' appeared. All subjects (or their responsible next of kin) provided written informed consent and were studied under a protocol approved by the Yale Human Investigation Committee.

\section{Cognitive and Functional Evaluation}

Subjects were evaluated using a number of cognitive tests and functional rating scales at the time of initial presentation (see table 2). Several of these measures were repeated longitudinally, at varying frequencies, depending on the different requirements of the research protocols in which subjects subsequently participated. Many subjects enrolled in multiple studies spanning several years. The cognitive performance of subjects was measured using the Mini-Mental State Examination (MMSE) [43] and the cognitive subscale of the Alzheimer's Disease Assessment Scale (ADAS-Cog) [44]. The MMSE evaluated memory, praxis and orientation on a scale of 0 (maximal impairment) to 30 (no impairment). The ADAS-Cog provided a broader test of cognition, using eleven subscales: word recall, naming, following commands, constructional praxis, ideational praxis, orientation, word recognition, language ability, comprehension of spoken language, word-finding difficulty and remembering test instructions. The ADAS-Cog is scored from 0 to 70 , with lower scores indicating better performance.

The functional capacity of subjects in ADLs was assessed using both the Instrumental Activities of Daily Living (IADL) questionnaire [45] and the Alzheimer's Disease Cooperative Study-Activities of Daily Living inventory (ADCS-ADL) [46]. The IADL was performed only once at baseline (and therefore included in retrospective but not prospective analyses) and evaluated everyday functioning along eight domains: using the telephone, shopping, food preparation, housekeeping, laundry, transportation, handling medications, and finances [45]. A score of 1 for a given domain indicated no impairment, with higher scores denoting greater de- grees of impairment. Since not all domains were valid for all subjects (e.g. men who never did laundry before AD onset), the IADL score was calculated as the sum of individual activity scores divided by the total possible valid points for that subject. The range of scores was therefore 0.27 (no impairment) to 1.00 (maximal impairment). The ADCS-ADL provides a comprehensive assessment of ADL performance across 28 functional domains and is scored from 0 (maximal impairment) to 78 (no impairment) [46]. Both the IADL and ADCS-ADL ratings were obtained on the basis of information provided by a caregiver actively involved in the patient's daily life.

Of the four cognitive and functional measures, the MMSE was performed on the entire sample $(n=366)$, whereas all other measures were available for only certain subsets of the subject population (as detailed in table 2). All subject data were obtained by trained raters who were unaware of the subjects' ApoE genotypes.

\section{Determination of ApoE Genotype}

DNA was prepared from whole blood in the laboratory of J.G. by standard salting-out procedures. Genotypes were obtained by the polymerase chain reaction (PCR)-restriction fragment length polymorphism method [47] using a PCR procedure slightly modified from Tsai et al. [48]. The PCR product was digested by HhaI (New England Biolabs) and subjected to electrophoresis in 5\% MetaPhor agarose (FMC Corp., Rochland, Me., USA). Gels were stained with ethidium bromide and DNA visualized by UV transillumination. The three alleles were scored as described by Hixson and Vernier [47]. Eight percent of genotypes were repeated as a quality check, with complete concordance.

\section{Statistical Analysis}

Subject characteristics (including demographics, disease characteristics, and concomitant therapies) were compared across gene dose groups using analysis of variance (ANOVA) for continuous variables or $\chi^{2}$ analysis for dichotomous variables. 
Table 2. Cognitive and functional data at baseline (mean $\pm \mathrm{SD})$

\begin{tabular}{llll}
\hline Variable & $\varepsilon 4$ non-carriers & $\varepsilon$ 4 heterozygotes & $\varepsilon$ 4 homozygotes \\
\hline \multirow{2}{*}{ MMSE $(\mathrm{n}=366)$} & $\mathrm{n}=156$ & $\mathrm{n}=159$ & $\mathrm{n}=51$ \\
\hline \multirow{2}{*}{ ADAS-Cog $(\mathrm{n}=300)$} & $\mathrm{n}=128$ & $17.0 \pm 5.5$ & $18.2 \pm 4.5$ \\
\hline \multirow{2}{*}{ IADL $(\mathrm{n}=353)$} & $26.6 \pm 11.7$ & $\mathrm{n}=127$ & $\mathrm{n}=45$ \\
\hline & $\mathrm{n}=154$ & $\mathrm{n}=151$ & $27.3 \pm 10.7$ \\
ADCS-ADL $(\mathrm{n}=188)$ & $0.65 \pm 0.19$ & $0.65 \pm 0.20$ & $\mathrm{n}=48$ \\
\hline
\end{tabular}

MMSE = Mini-Mental State Examination; ADAS-Cog = Alzheimer's Disease Assessment Scale-Cognitive Subscale; IADL = Instrumental Activities of Daily Living; ADCS$\mathrm{ADL}=$ Alzheimer's Disease Cooperative Study-Activities of Daily Living.

Gene dose groups did not differ significantly in any cognitive or functional variable adjusted for disease duration, as well as age, sex, and education.
The effect of ApoE $\varepsilon 4$ dose ( 0,1 , or 2 copies) on the rate of $\mathrm{AD}$ progression was analyzed using both retrospective and prospective techniques. The retrospective analyses examined cross-sectional cognitive (MMSE, ADAS-Cog) and functional (IADL, ADCS$\mathrm{ADL}$ ) data obtained at each subject's initial visit, while controlling for the duration of symptoms by analysis of covariance (ANCOVA). Although disease duration was the essential covariate in all retrospective analyses, age, sex, and educational attainment were also included as covariates in the ANCOVA models.

Prospective analyses of disease progression were also conducted for the MMSE, ADAS-Cog (including its word recall and word recognition subtests, in light of the recent report of Hirono et al. [32] that change in these subtests was related to ApoE $\varepsilon 4$ dose), and ADCS-ADL for all subjects who had at least three observations spanning at least 6 months of research participation. For these analyses, an annualized rate of change in performance on each scale was calculated by least-squares regression, using all available measurements for each subject. Rates of change were compared across ApoE $\varepsilon 4$ dose groups by ANCOVA, controlling for age, sex, and education.

\section{Results}

\section{Subject Characteristics}

The overall subject sample $(\mathrm{n}=366)$ was comprised of $\varepsilon 4$ homozygotes $(n=51), \varepsilon 4$ heterozygotes $(n=159)$ and non-carriers $(\mathrm{n}=156)$. Table 1 summarizes the characteristics of each ApoE $\varepsilon 4$ dose group with regard to demographics, disease characteristics, and baseline concomitant treatments. The $\varepsilon 4$ dose groups did not differ significantly in age $(\mathrm{F}=2.37 ; \mathrm{df}=2,363 ; \mathrm{p}=0.10)$, $\operatorname{sex}\left(\chi^{2}=2.33\right.$; $\mathrm{df}=2 ; \mathrm{p}=0.31)$, education $(\mathrm{F}=1.56 ; \mathrm{df}=2,363 ; \mathrm{p}=0.21)$, onset age $(\mathrm{F}=2.40 ; \mathrm{df}=2,363 ; \mathrm{p}=0.09)$, duration of symp- toms $(\mathrm{F}=0.08 ; \mathrm{df}=2,363 ; \mathrm{p}=0.93)$, or family history of $\operatorname{AD}\left(\chi^{2}=3.93 ; \mathrm{df}=2 ; \mathrm{p}=0.14\right)$. Finally, they did not differ in baseline use of cholinesterase inhibitors $\left(\chi^{2}=1.20\right.$; $\mathrm{df}=2 ; \mathrm{p}=0.55)$, antipsychotics $\left(\chi^{2}=2.36 ; \mathrm{df}=2 ; \mathrm{p}=0.31\right)$, antidepressants $\left(\chi^{2}=1.70 ; \mathrm{df}=2 ; \mathrm{p}=0.43\right)$, or high-dose vitamin $\mathrm{E}\left(\chi^{2}=0.19 ; \mathrm{df}=2 ; \mathrm{p}=0.91\right)$.

\section{Retrospective Analysis of Cognitive and Functional Progression}

Table 2 presents a summary of the retrospective analyses of cognitive and functional progression in $\mathrm{AD}$ patients. It specifically contains the baseline cognitive and functional data according to ApoE $\varepsilon 4$ dose.

MMSE. MMSE performance was analyzed in the overall sample of 366 subjects. Gene dose groups did not differ significantly in MMSE performance $(\mathrm{F}=1.06$; $\mathrm{df}=2,359$; $\mathrm{p}=0.35$ ), controlling for disease duration, age, sex, and education.

ADAS-Cog. ADAS-Cog performance was analyzed in a sub-sample of 300 subjects. The demographic profile of this sub-sample and all others analyzed below did not differ from that of the overall sample characterized in table 1. Gene dose groups did not differ significantly in ADAS-Cog performance $(\mathrm{F}=0.43 ; \mathrm{df}=2,293 ; \mathrm{p}=0.65)$, controlling for disease duration, age, sex, and education.

$I A D L$. IADL performance was analyzed in a sub-sample of 353 subjects. Gene dose groups did not differ significantly in IADL performance $(\mathrm{F}=1.09 ; \mathrm{df}=2,346 ; \mathrm{p}=$ 0.34 ), controlling for disease duration, age, sex, and education. 
Table 3. Prospective analysis of cognitive and functional progression (mean $\pm \mathrm{SD}$ )

\begin{tabular}{lccc}
\hline Variable & $\varepsilon 4$ non-carriers & $\varepsilon 4$ heterozygotes & $\varepsilon 4$ homozygotes \\
\hline & $\mathrm{n}=101$ & $\mathrm{n}=97$ & $\mathrm{n}=34$ \\
MMSE annual change $(\mathrm{n}=232)$ & $-3.18 \pm 3.90$ & $-3.02 \pm 3.20$ & $-3.20 \pm 4.14$ \\
Number of observations & $7.1 \pm 3.2$ & $6.4 \pm 2.8$ & $6.8 \pm 3.8$ \\
Duration of observation, years & $1.80 \pm 1.19$ & $1.81 \pm 1.33$ & $1.67 \pm 1.34$ \\
\hline & $\mathrm{n}=88$ & $\mathrm{n}=80$ & $\mathrm{n}=30$ \\
ADAS-Cog annual change $(\mathrm{n}=198)^{1}$ & $6.03 \pm 9.92$ & $6.09 \pm 8.60$ & $6.33 \pm 6.85$ \\
Number of observations & $9.4 \pm 5.2$ & $8.9 \pm 4.8$ & $10.4 \pm 5.6$ \\
Duration of observation, years & $1.55 \pm 1.11$ & $1.62 \pm 1.28$ & $1.80 \pm 1.39$ \\
\hline & $\mathrm{n}=75$ & $\mathrm{n}=75$ & $\mathrm{n}=22$ \\
ADCS-ADL annual change $(\mathrm{n}=172)$ & $-10.28 \pm 11.85$ & $-9.96 \pm 8.66$ & $-12.58 \pm 14.53$ \\
Number of observations & $7.6 \pm 3.5$ & $6.6 \pm 2.8$ & $6.7 \pm 2.7$ \\
Duration of observation, years & $1.54 \pm 1.10$ & $1.28 \pm 0.89$ & $1.20 \pm 0.85$ \\
\hline
\end{tabular}

MMSE = Mini-Mental State Examination; ADAS-Cog = Alzheimer's Disease Assessment Scale-Cognitive Subscale; ADCS-ADL = Alzheimer's Disease Cooperative StudyActivities of Daily Living.

Data displayed are longitudinal rates of change per year computed by linear regression.

${ }^{1}$ Rates of ADAS-Cog change are positive because lower scores indicate better performance.
ADCS-ADL. ADCS-ADL performance was analyzed in a sub-sample of 188 subjects. Gene dose groups did not differ significantly in ADCS-ADL performance $(\mathrm{F}=2.81$; $\mathrm{df}=2,181 ; \mathrm{p}=0.063)$, controlling for disease duration, education, and age.

\section{Prospective Analysis of Cognitive and Functional \\ Progression}

Table 3 presents a summary of the prospective analyses of cognitive and functional progression in $\mathrm{AD}$ patients. It specifically contains the annualized rates of change for cognitive and functional measures according to ApoE $\varepsilon 4$ dose.

MMSE. Annualized rate of change in MMSE performance was analyzed in a sub-sample of 232 subjects. Subjects received an average of 6.7 assessments (range 3-18) spanning 1.8 years of follow-up (range $0.5-6.4$ ). The rate of MMSE change did not differ significantly across gene dose groups $(\mathrm{F}=0.00 ; \mathrm{df}=2,226 ; \mathrm{p}=1.00$; covariates: age, sex, education).

ADAS-Cog. Annualized rate of change in ADAS-Cog performance was analyzed in a sub-sample of 198 subjects. Subjects received an average of 9.4 assessments (range 3-25) spanning 1.6 years of follow-up (range 0.55.8). The rate of ADAS-Cog change did not differ significantly across gene dose groups $(\mathrm{F}=0.01$; $\mathrm{df}=2,192$; $p=0.99$; covariates: age, sex, education). In light of the recent report of Hirono et al. [32] that change in ADASCog memory subtest scores, in particular, was related to ApoE $\varepsilon 4$ dose, we also examined the annualized rate of change on the word recall and word recognition subtests and found no difference across gene dose groups (word recall: $\mathrm{F}=0.69 ; \mathrm{df}=2,190 ; \mathrm{p}=0.50$; word recognition: $\mathrm{F}=2.02, \mathrm{df}=2,190 ; \mathrm{p}=0.14$; covariates: age, sex, education).

$A D C S-A D L$. Annualized rate of change in ADCS-ADL performance was analyzed in a sub-sample of 172 subjects. Subjects received an average of 7.1 assessments (range 3-18) spanning 1.4 years of follow-up (range 0.54.9). The rate of ADCS-ADL change did not differ significantly across gene dose groups $(\mathrm{F}=0.41 ; \mathrm{df}=2,166$; $\mathrm{p}=0.66$; covariates: age, sex, education).

\section{Discussion}

Although several previous investigators have examined the relationship between ApoE $\varepsilon 4$ dose and the rate of progression in $\mathrm{AD}$, the present study is the first to employ concurrent retrospective and prospective analyses in a large cohort of patients. In retrospective analyses we found no effect of ApoE $\varepsilon 4$ dose on baseline cross-sectional cogni- 
Table 4. Comparison with relevant studies

\begin{tabular}{|c|c|c|c|c|}
\hline Study (first author) & $\begin{array}{l}\text { Subject } \\
\text { sample }\end{array}$ & Cognitive measures & $\begin{array}{l}\text { Functional } \\
\text { measures }\end{array}$ & $\begin{array}{l}\text { Analysis (mean duration } \\
\text { of follow-up, years) }\end{array}$ \\
\hline \multicolumn{5}{|c|}{ ApoE $\varepsilon 4$ has absent or equivocal effect on cognitive or functional decline } \\
\hline Basun (1995) [17] & 60 & MMSE & & Prospective (3) \\
\hline Asada (1996) [18] & 70 & CDR, HDSR & & Prospective (2.2) \\
\hline Dal Fornoe (1996) [19] & 78 & MMSE, cognitive battery & PGDRS & Prospective $(3.5)^{1}$ \\
\hline Gomez-Isla (1996) [8] & 153 & BDRS & RIL & Prospective (2.6) \\
\hline Growdon (1996) [20] & 66 & Cognitive battery & & Prospective (2) \\
\hline Holmes (1996) [21] & 145 & MMSE, BDRS & & Prospective (1.3) \\
\hline Kurz (1996) [22] & 61 & MMSE, CAMCOG & DS-CAMDEX & Prospective (3.0) \\
\hline Murphy (1997) [23] & 86 & MMSE & & Prospective (3.6) \\
\hline Jonker (1998) [24] & 34 & CAMCOG & & Prospective (3) \\
\hline Lehtovirta (1998) [25] & 31 & MMSE & & Prospective (3) \\
\hline Farlow (1999) [26] & 373 & ADAS-Cog & & Prospective (0.4) \\
\hline Slooter (1999) [27] & 85 & MMSE & & Prospective (4.4) \\
\hline Aerssens (2001) [28] & 504 & ADAS-Cog & $\mathrm{DAD}$ & Prospective $(\leq 1)$ \\
\hline Mori (2002) [29] & 55 & MMSE, ADAS-Cog & & Prospective (1) \\
\hline Kleiman, this study & 366 & MMSE, ADAS-Cog & IADL, ADCS-ADL & $\begin{array}{l}\text { Retrospective/ } \\
\text { prospective (1.6) }\end{array}$ \\
\hline \multicolumn{5}{|c|}{ ApoE $\varepsilon 4$ accelerates rate of cognitive decline } \\
\hline Craft (1998) [30] & 201 & DRS & & Pros \\
\hline Kanai (1999) [31] & 33 & MMSE & & Prospective (1.7) \\
\hline Hirono (2003) [32] & 64 & ADAS-Cog & & Prospective (1) \\
\hline \multicolumn{5}{|c|}{ ApoE $\varepsilon 4$ decelerates rate of cognitive decline } \\
\hline Frisoni (1995) [33] & 62 & MMSE, CDR & & $\begin{array}{l}\text { Retrospective/ } \\
\text { prospective (1) }\end{array}$ \\
\hline Stern (1997) [34] & 99 & mMMS & & Prospective (3.6) \\
\hline \multicolumn{5}{|c|}{$\begin{array}{l}\text { Subject sample refers to the number of subjects who had at least one follow-up assessment on at least one } \\
\text { listed cognitive or functional measure. MMSE = Mini-Mental State Examination; CDR = Clinical Dementia Rat- } \\
\text { ing; HDSR = Hasegawa's Dementia Screening-Revised; PGDRS = Psychogeriatric Dependency Rating Scale; } \\
\text { BDRS = Blessed Dementia Rating Scale; RIL = Record of Independent Living; CAMCOG = Cambridge Cognitive } \\
\text { Examination; DS-CAMDEX = Dementia Scale of Cambridge Mental Disorders of the Elderly Examination; } \\
\text { ADAS-Cog = Alzheimer's Disease Assessment Scale-Cognitive Subscale; DAD = Disability Assessment in De- } \\
\text { mentia; IADL = Instrumental Activities of Daily Living; ADCS-ADL = Alzheimer's Disease Cooperative Study- } \\
\text { Activities of Daily Living Scale; DRS = Dementia Rating Scale; mMMS = Modified Mini-Mental State. } \\
\quad 13.5 \text { years for most tests; } 5.5 \text { years for PGDRS. }\end{array}$} \\
\hline
\end{tabular}

tive or functional measures, while controlling for estimated duration of symptoms. In prospective analyses we observed no effect of $\varepsilon 4$ dose on longitudinal rates of change for each measure as computed by linear regression.

The vast majority of ApoE $\varepsilon 4$ progression studies have employed prospective longitudinal measurement, although one prior study [33] utilized a cross-sectional retrospective analysis. Retrospective designs have the inherent drawback of requiring an estimation of disease onset by the recollection of an informant. However, they may permit consideration of a longer and earlier segment of the disease course. Prospective analyses are limited by fol- lowing patients for only a small portion of their disease course (0.5-4 years, see table 4$)$ and neglect the earliest stages of disease. Thus, retrospective and prospective analyses may provide complimentary information. The fact that both types of analysis yielded essentially the same results in the present study lends additional credence to the conclusions.

Our method of retrospective analysis differed somewhat from that of Frisoni et al. [33] who estimated MMSE at onset of symptoms using an education norms-based algorithm derived from cognitively unimpaired elders. We considered a similar algorithm but found that educa- 
tional attainment was not a significant predictor of MMSE score (or ADAS-Cog) in a healthy elderly sample with demographics comparable to our $\mathrm{AD}$ patient group (data not shown). This difference may be due to the fact that our samples were more highly and homogeneously educated than those of Frisoni et al.

Comparison to Other ApoE $\varepsilon 4$ AD Progression Studies

Table 4 situates the present results within the broader literature. Ours is among only a few ApoE $\varepsilon 4 \mathrm{AD}$ progression studies to consider both cognitive and functional outcome measures in the same cohort of subjects.

Cognitive Decline. Our finding that ApoE $\varepsilon 4$ dose neither accelerated nor decelerated the rate of cognitive decline in $\mathrm{AD}$ accords with the vast majority of published studies on the subject $[8,17-19,21-28]$. However, a smaller number of studies found that $\mathrm{ApoE} \varepsilon 4$ is associated with either an accelerated [30-32] or decelerated [33,34] rate of cognitive decline. Discrepancies in the literature may owe to sampling error, particularly in those studies with few $\varepsilon 4$ homozygotes. Only two previous studies used samples comparable in size to the present one - Farlow et al. [26] and Aerssens et al. [28]. These studies both analyzed placebo-treated patients from pooled clinical trial data and thus had relatively shorter follow-up periods than the present study. Nonetheless, both shared our finding that ApoE genotype did not influence the rate of cognitive decline.

That the majority of studies have found global cognitive progression to be unrelated to ApoE $\varepsilon 4$ genotype in $\mathrm{AD}$ does not preclude the possibility of more selective cognitive effects of the $\varepsilon 4$ allele. MRI studies have suggested accelerated atrophy of medial temporal lobe structures that subserve memory function in $\mathrm{AD}$ patients who carry $\varepsilon 4[29,49-52]$, and $\varepsilon 4$ homozygotes have been reported to have more severe memory loss cross-sectionally than other $\mathrm{AD}$ patients [53]. In a recent longitudinal study of $64 \mathrm{AD}$ patients, Hirono et al. [32] reported that 1-year changes in memory subtests of the ADAS-Cog - as well as total ADAS-Cog - were significantly correlated with ApoE $\varepsilon 4$ dose. However, in our sub-sample of 198 patients who were administered the ADAS-Cog on average 9.4 times over 1.6 years, we were unable to replicate this finding. We observed no difference in the annualized rate of change in word recall and word recognition subtests (or total ADAS-Cog) across gene dose groups.

Functional Decline. Our finding that ApoE $\varepsilon 4$ allele dose did not influence the rate of functional decline in $\mathrm{AD}$ accords with the few available studies on the subject. Dal
Forno et al. [19] found that a small number of $\varepsilon 4$ homozygotes $(n=12)$ declined faster than patients lacking the $\varepsilon 4$ allele $(n=25)$ on the Physical Capacity subscale of Psychogeriatric Dependency Rating Scale (PGDRS), although other pairwise comparisons between gene dose groups were not significant. Gomez-Isla et al. [8] found no effect of ApoE $\varepsilon 4$ genotype on the ADL scale of the Record of Independent Living in $141 \mathrm{AD}$ patients followed longitudinally (mean follow-up period 31.8 months). Kurz et al. [22] observed no difference between $\varepsilon 4$ carriers and non-carriers in everyday performance rated with the Dementia Scale of the Cambridge Mental Disorders of the Elderly Examination (CAMDEX) in $64 \mathrm{AD}$ patients who were followed for up to 3 years. Aerssens et al. [28] examined rates of change in score on the Disability Assessment for Dementia (DAD) in 504 placebo-treated $A D$ patients enrolled in clinical trials (3-12 months duration) and reported no effect of $\varepsilon 4$ dose. These collective findings suggest that ApoE genotype is not a meaningful predictor of the rate of functional decline in $\mathrm{AD}$ patients.

\section{Interpretation of a Negative Effect of ApoE $\varepsilon 4$ on $A D$ Progression}

If a preponderance of studies have found no evidence that the ApoE $\varepsilon 4$ allele modulates $\mathrm{AD}$ progression after onset, this has been difficult to reconcile with the fact that $\varepsilon 4$ accelerates disease onset $[4,5]$ and promotes the hallmark neuropathology of AD [7-11]. Several writers have commented on the likely dissociation between processes leading to the onset of $\mathrm{AD}$ and those that determine its clinical course [54-56]. Plassman and Breitner [55] noted that if the dementia of $\mathrm{AD}$ progresses at a rate independent of ApoE genotype, this would imply a shift in pathogenetic mechanisms around the time of clinical onset. Roses [57] has proposed that the disease process becomes 'autocatalytic' at that point. Chapman et al. [56], using evidence from studies of the onset and progression of $\mathrm{AD}$ and multiple sclerosis, suggested that ApoE $\varepsilon 4$ influences disease pathology by diminishing the efficacy of neuronal maintenance and repair. In the case of $\mathrm{AD}$, which has a long period of biologic deterioration prior to clinical diagnosis, $\varepsilon 4$ carriers would be expected to reach the clinical threshold significantly earlier than non-carriers, as they may be less capable of repairing neuronal damage during the subclinical phase of the disease. Among patients who have already reached the clinical threshold, however, different rates of neuronal deterioration would not necessarily create observable differences in cognitive or functional performance. 
We would further propose that the apparent absence of an ApoE $\varepsilon 4$ effect in modulating AD progression may relate to the presence in $\varepsilon 4$-negative subjects of diseases other than $\mathrm{AD}$, and especially, of genetically different forms of $\mathrm{AD}$, influenced by loci other than ApoE. First, the majority of progression studies utilize subjects without autopsy confirmation of diagnosis. The $\varepsilon 4$-negative samples in these studies are likely to contain a higher percentage of subjects with etiologies of dementia for which $\varepsilon 4$ is a weaker risk factor, e.g., frontotemporal dementia $[58,59]$. If the rate of progression is indeed more rapid in frontotemporal dementia compared to $\mathrm{AD}[60]$, this phenomenon might offset a small effect of $\varepsilon 4$ in accelerating clinical deterioration in AD patients. Second, comparison of ApoE $\varepsilon 4$-positive and -negative $\mathrm{AD}$ samples has generally assumed that these populations differ only by the presence or absence of the $\varepsilon 4$ allele, whereas they are likely to differ systematically by other genetic or environmental factors as well. Family history of AD has been shown to be a risk factor for $\mathrm{AD}$ beyond the effect of $\varepsilon 4$ alone [55], which is one reflection of the existence of additional genetic or environmental risk factors for AD. Samples of $\varepsilon 4$-negative $\mathrm{AD}$ patients are likely enriched for these factors [61], which may in turn be associated with a form of $\mathrm{AD}$ conferring a later age of onset but equal or increased rates of clinical progression. Thus, the growing body of research examining phenotypic associations of ApoE $\varepsilon 4$ in $\mathrm{AD}$ samples is almost certainly confounded by an effective disequilibrium with other factors.

This study certainly has a number of potential limitations that warrant comment. First, our subjects were drawn from participants in research protocols in an academic medical center and may differ demographically from a population sample [62]. In particular, our subject observations were performed largely during the course of trials of investigational drugs whose effects on the course of $\mathrm{AD}$ progression might obscure that of genotype alone. However, most of the experimental treatments in question were ultimately found not to influence the progression of $\mathrm{AD}$ symptoms, and any small effect was likely distributed randomly with respect to ApoE genotype, as borne out for several specific concomitant therapies. A second potential selection bias is signaled by the fact that our ApoE $\varepsilon 4$ dose groups did not quite differ $(p=0.09)$ in age of disease onset, thus diverging from most epidemiologic samples [5]. Conceivably, $\varepsilon 4$ would only influence the rate of disease progression insofar as it was also associated with earlier onset. Furthermore, our retrospective analysis of disease progression was potentially limited by recall bias, as disease onset was estimated by the recollec- tion of relatives. However, relatives' prospective and retrospective ratings have been found to be in reasonably close agreement, particularly when the AD patient still resides in the community [63]. Moreover, inaccuracies in retrospective onset determination are unlikely to show systematic biases with respect to ApoE genotype. Finally, our statistical model for prospective analyses (comparison of linear regression slopes across ApoE groups) was potentially limited by considerable variability between subjects in numbers of observations, intervals between observations, and duration of follow-up. However, this method is probably reasonable and unbiased insofar as these sources of variation are randomly distributed with respect to ApoE genotype.

In conclusion, we observed no association between ApoE $\varepsilon 4$ dose and any of the retrospective or prospective measures of cognitive or functional decline in this AD patient sample. Although ApoE $\varepsilon 4$ increases the risk for $\mathrm{AD}$ and decreases the age of disease onset in population studies, it did not significantly influence the rate of disease progression in cognitive or functional domains in our sample.

\section{Acknowledgements}

The authors thank Ann Marie Lacobelle for technical assistance. This research was supported in part by NIH Clinical Neuroscience Mental Health Research Training Grant, as well as K24DA15105 (J.G.), and P30-MH30929. 


\section{References}

1 Saunders AM, Strittmatter WJ, Schmechel DE, St George-Hyslop PH, Pericak-Vance MA, Joo BS, Rosi BL, Gusella JF, Crapper-MacLachlan DR, Alberts MJ, Hulette C, Crain B, Goldgaber D, Roses AD: Association of apolipoprotein E allele $\varepsilon 4$ with late-onset familial and sporadic Alzheimer's disease. Neurology 1993;43:1467-1472.

-2 Martins RN, Clarnette R, Fisher C, Broe GA, Brooks WS, Montgomery P, Gandy SE: ApoE genotypes in Australia: roles in early and late onset Alzheimer's disease and Down syndrome. Neuroreport 1995;6:1513-1516.

-3 Utermann G, Langenbeck U, Beisiegel U, Weber W: Genetics of the apolipoprotein E system in man. Am J Hum Genet 1980;32:339347.

4 Corder EH, Saunders AM, Strittmatter WJ, Schmechel DE, Gaskell PC, Small GW, Roses AD, Haines JL, Pericak-Vance MA: Gene dose of apolipoprotein E type 4 allele and the risk of Alzheimer's disease in late onset families. Science 1993;261:921-923.

5 Farrer LA, Cupples LA, Haines JL, Hyman BT, Kukull WA, Mayeux R, Myers RH, PericakVance MA, Risch NJ, van Duijn CM: Effects of age, sex and ethnicity on the association between apolipoprotein $\mathrm{E}$ genotype and Alzheimer disease - a meta-analysis. JAMA 1997; 278:1349-1356.

6 Talbot C, Lendon CL, Craddock N, Shears S, Morris JC, Goate A: Protection against Alzheimer's disease with apoE $\varepsilon 2$. Lancet 1994; 343:1432-1433.

7 Nagy NS, Esiri MM, Jobst KA, Johnston C, Litchfield S, Sim E, Smith AD: Influence of the apolipoprotein E genotype on amyloid deposition and neurofibrillary tangle formation in Alzheimer's disease. Neuroscience 1995;69: 757-761.

-8 Gomez-Isla T, West HL, Rebeck GW, Harr SD, Growdon JH, Locascio JJ, Perls TT, Lipsitz LA, Hyman BT: Clinical and pathological correlates of apolipoprotein E $\varepsilon 4$ in Alzheimer's disease. Ann Neurol 1996;39:62-70.

$\checkmark 9$ Schmechel DE, Saunders AM, Strittmatter WJ, Crain B, Hulette C, Joo SH, Pericak-Vance MA, Goldgaber D, Roses AD: Increased amyloid $\beta$-peptide deposition as a consequence of apolipoprotein E genotype in late-onset Alzheimer's disease. Proc Natl Acad Sci USA 1993;90:9649-9653.

-10 Norrman J, Brookes AJ, Yates C, St Clair D: Apolipoprotein E genotype and its effect on duration and severity of early and late onset Alzheimer's disease. Br J Psychiatry 1995;167: 533-536.

-11 Bennett DA, Wilson RS, Schneider JA, Evans DA, Aggarwal NT, Arnold SE, Cochran EJ, Berry-Kravis E, Bienias JL: Apolipoprotein E $\varepsilon 4$ allele, $\mathrm{AD}$ pathology, and the clinical expression of Alzheimer's disease. Neurology 2003;60:246-252.
12 Higgins GA, Large CH, Rupniak HT, Barnes JC: Apolipoprotein E and Alzheimer's disease: a review of recent studies. Pharmacol Biochem Behav 1997;56:675-685

13 Puglielli L, Tanzi RE, Kovacs DM: Alzheimer's disease: the cholesterol connection. Nat Neurosci 2003;6:345-351.

14 Strittmatter WJ, Saunders AM, Schmechel DE, Pericak-Vance MA, Enghild J, Salvesen GS, Roses AD: Apolipoprotein E: high-avidity binding to $\beta$-amyloid and increased frequency of type 4 allele in late-onset familial Alzheimer disease. Proc Natl Acad Sci USA 1993; 90:1977-1981.

15 Munson GW, Roher AE, Kuo YM, Gilligan SM, Reardon CA, Getz GS, Ladu MJ: SDS-stable complex formation between native apoliproprotein $\varepsilon 3$ and $\beta$-amyloid peptides. Biochemistry 2000;39:16119-16124.

16 Strittmatter WJ, Roses AD: Apolipoprotein E and Alzheimer's disease. Annu Rev Neurosci 1996;19:53-77.

17 Basun H, Grut M, Winblad B, Lannfelt L: Apolipoprotein $\varepsilon 4$ allele and disease progression in patients with late-onset Alzheimer's disease. Neurosci Lett 1995;183:32-34.

18 Asada T, Kariya T, Yamagata Z, Kinoshita T, Asaka A: ApoE $\varepsilon 4$ allele and cognitive decline in patients with Alzheimer's disease. Neurology 1996;47:603.

19 Dal Forno G, Rasmusson X, Brandt J, Carson KA, Brookmeyer R, Troncoso J, Kawas CH: Apolipoprotein E genotype and rate of decline in probable Alzheimer's disease. Arch Neurol 1996;53:345-350.

20 Growdon JH, Locascio JJ, Corkin S, GomezIsla T, Hyman BT: Apolipoprotein E genotype does not influence rates of cognitive decline in Alzheimer's disease. Neurology 1996;47:444448.

21 Holmes C, Levy R, McLoughlin DM, Powell JF, Lovestone S: Apolipoprotein E: non-cognitive symptoms and cognitive decline in late onset Alzheimer's disease. J Neurol Neurosurg Psychiatry 1996;61:580-583.

22 Kurz A, Egensperger R, Haupt M, Lautenschlager N, Romero B, Graeber MB, Müller U: Apolipoprotein E $\varepsilon 4$ allele, cognitive decline, and deterioration of everyday performance in Alzheimer's disease. Neurology 1996;47:440 443.

23 Murphy GM, Taylor J, Kraemer HC, Yesavage J, Tinklenberg JR: No association between apolipoprotein E $\varepsilon 4$ allele and rate of decline in Alzheimer's disease. Am J Psychiatry 1997; 154:603-608.

24 Jonker C, Schmand B, Lindeboom J, Havekes LM, Launer LJ: Association between apolipoprotein $\mathrm{E} \varepsilon 4$ and the rate of cognitive decline in community-dwelling elderly individuals with and without dementia. Arch Neurol 1998;55:1065-1069.
25 Lehtovirta M, Kuikka J, Helisalmi S, Hartikainen P, Mannermaa A, Ryynänen M, Riekkinen P Sr, Soininen H: Longitudinal SPECT study in Alzheimer's disease: relation to apolipoprotein E polymorphism. J Neurol Neurosurg Psychiatry 1998;64:742-746.

26 Farlow MR, Cyrus PA, Nadel A, Lahiri DK, Brashear A, Gulanski B: Metrifonate treatment of AD - influence of APOE genotype. Neurology 1999;53:2010-2016.

-27 Slooter AJC, Houwing-Duistermaat JJ, van Harskamp F, Cruts M, van Broeckhoven C, Breteler MMB, Hofman A, Stijnen T, van Duijn CM: Apolipoprotein E genotype and progression of Alzheimer's disease: the Rotterdam study. J Neurol 1999;246:304-308.

-28 Aerssens J, Raeymaekers P, Lilienfeld S, Geerts $\mathrm{H}$, Konings F, Parys W: APOE genotype: no influence on galantamine treatment efficacy nor on rate of decline in Alzheimer's disease. Dement Geriatr Cogn Disord 2001;12:6977.

29 Mori E, Lee K, Yasuda M, Hashimoto M, Kazui H, Hirono N, Matsui M: Accelerated hippocampal atrophy in Alzheimer's disease with apolipoprotein E $\varepsilon 4$ allele. Ann Neurol 2002; 51:209-214.

30 Craft S, Teri L, Edland SD, Kukull WA, Schellenberg G, McCormick WC, Bowen JD, Larson EB: Accelerated decline in apolipoprotein E- $\varepsilon 4$ homozygotes with Alzheimer's disease. Neurology 1998;51:149-153.

31 Kanai M, Shizuka M, Urakami K, Matsubara E, Harigaya Y, Okamoto K, Shoji M: Apolipoprotein $\varepsilon 4$ accelerates dementia and increases cerebrospinal fluid tau levels in Alzheimer's disease. Neurosci Lett 1999;267:65-68.

32 Hirono N, Hashimoto M, Yasuda M, Kazui H, Mori E: Accelerated memory decline in $\mathrm{Alz}$ heimer's disease with apolipoprotein $\varepsilon 4$ allele. J Neuropsychiatry Clin Neurosci 2003;15: 354-358.

33 Frisoni GB, Govoni S, Geroldi C, Bianchetti A, Calabresi L, Franceschini G, Trabucchi M: Gene dose of the $\varepsilon 4$ allele of apolipoprotein $\mathrm{E}$ and disease progression in sporadic late-onset Alzheimer's disease. Ann Neurol 1995;37: 596-604.

34 Stern Y, Brandt J, Albert M, Jacobs DM, Liu X, Bell K, Marder K, Sano M, Albert S, Castenada CD, Bylsma F, Tycko B, Mayeux R: The absence of an apolipoprotein $\varepsilon 4$ allele is associated with a more aggressive form of Alzheimer's disease. Ann Neurol 1997;41:615-620.

35 Gutterman EM, Markowitz JS, Lewis B, Fillit $\mathrm{H}$ : Cost of Alzheimer's disease and related dementia in managed-Medicare. J Am Geriatr Soc 1999;47:1065-1071.

36 Clyburn LD, Stones MJ, Hadjistavropoulos T, Tuokko H: Predicting caregiver burden and depression in Alzheimer's disease. J Gerontol B Psychol Sci Soc Sci 2000;55:S2-S13. 
\37 Tekin S, Fairbanks LA, O’Connor S, Rosenberg S, Cummings JL: Activities of daily living in Alzheimer's disease: neuropsychiatric, cognitive and medical illness influences. Am J Geriatr Psychiatry 2001;9:81-86.

$\checkmark 38$ Boyle PA, Malloy PF, Salloway S, Cahn-Weiner DA, Cohen R, Cummings JL: Executive dysfunction and apathy predict functional impairment in Alzheimer disease. Am J Geriatr Psychiatry 2003;11:214-221.

-39 McKhann G, Drachman D, Folstein M, Katzman R, Price D, Stadlan EM: Clinical diagnosis of Alzheimer's disease: report of the NINCDS-ADRDA work group under the auspices of Department of Health and Human Services Task Force on Alzheimer's disease. Neurology 1984;34:939-944.

-40 Mirra SS, Heyman A, McKeel D, Sumi SM, Crain BJ, Brownlee LM, Vogel FS, Hughes JP, van Belle G, Berg L: The consortium to establish a registry for Alzheimer's disease (CERAD). II. Standardization of the neuropathologic assessment of Alzheimer's disease. Neurology 1991;41:479-486.

41 Breitner JCS, Folstein MF: Familial Alzheimer's disease: a prevalent disorder with specific clinical features. Psychol Med 1984;14: 63-80.

-42 Silverman JM, Breitner JCS, Mohs RC, Davis KL: Reliability of the family history method in genetic studies of Alzheimer's disease and related dementias. Am J Psychiatry 1986;143: 1279-1282.

43 Folstein MF, Folstein SE, McHugh PR: 'Minimental state': a practical method for grading the cognitive state of patients for the clinician. J Psychiatr Res 1975;12:189-198.

-44 Rosen WG, Mohs RC, Davis KL: A new rating scale for Alzheimer's disease. Am J Psychiatry 1984;141:1356-1364.

45 Lawton MP, Brody EM: Assessment of older people: self-maintaining and instrumental activities of daily living. Gerontologist 1969;9: 179-186.
46 Galasko D, Bennett D, Sano M, Ernesto C, Thomas R, Grundman M, Ferris S: An inventory to assess activities of daily living for clinical trials in Alzheimer's disease. The Alzheimer's Disease Cooperative Study. Alzheimer Dis Assoc Disord 1997;11:33-39.

47 Hixson JE, Vernier DT: Restriction isotyping of human apolipoprotein E by gene amplification and cleavage with HhaI. J Lipid Res 1990; 31:545-548.

48 Tsai MS, Tangalos EG, Petersen RC, Smith GE, Schaid DJ, Kokmen E, Ivnik RJ, Thibodeau SN: Apolipoprotein E: risk factor for Alzheimer disease. Am J Hum Genet 1994;54:643649.

49 Lehtovirta M, Soininen H, Laakso MP, Partanen K, Helisalmi S, Mannermaa A, Ryynänen M, Kuikka J, Hartikainen P, Riekkinen PJ: SPECT and MRI analysis in Alzheimer's disease: relation to apolipoprotein E $\varepsilon 4$ allele. J Neurol Neurosurg Psychiatry 1996;60:644649.

50 Geroldi C, Pihlajamäki M, Laakso MP, DeCarli C, Beltramello A, Bianchetti A, Soininen $\mathrm{H}$, Trabucchi M, Frisoni GB: APOE- $\varepsilon 4$ is associated with less frontal and more medial temporal lobe atrophy in AD. Neurology 1999;53:1825-1832.

51 Van Dyck CH: Neuroimaging in Alzheimer's disease: relevance for treatment. Curr Psychiatry Rep 2001;3:13-19.

52 Basso M, Gelernter J, Yang J, MacAvoy MG, Varma P, Bronen RA, van Dyck CH: Apolipoprotein $\mathrm{E} \varepsilon 4$ is associated with atrophy of the amygdala in Alzheimer's disease. Neurobiol Aging 2005, in press.

53 Lehtovirta M, Soininen H, Helisalmi S, Mannermaa A, Helkala EL, Hartikainen P, Hanninen T, Ryynänen M, Riekkinen P Sr: Clinical and neuropsychological characteristics in familial and sporadic Alzheimer's disease: relation to apolipoprotein E polymorphism. Neurology 1996;46:413-419.

54 Corder EH, Saunders AM, Strittmatter WJ, Schmechel DE, Gaskell PCJ, Rimmler JB, Locke PA, Conneally PM, Schmader KE, Tanzi RE, et al: Apolipoprotein E, survival in Alzheimer's disease patients, and the competing risks of death and Alzheimer's disease. Neurology 1995;45:1323-1328.
55 Plassman BL, Breitner JCS: Apolipoprotein E and cognitive decline in Alzheimer's disease. Neurology 1996;47:317-320.

56 Chapman J, Korezyn AD, Karussis DM, Michaelson DM: The effects of APOE genotype on age at onset and progression of neurodegenerative diseases. Neurology 2001;57:14821485.

57 Roses AD: Apolipoprotein E alleles as risk factors in Alzheimer disease. Annu Rev Med 1996;47:387-400.

58 Geschwind D, Karrim J, Nelson SF, Miller B: The apolipoprotein E $\varepsilon 4$ allele is not a significant risk factor for frontotemporal dementia. Ann Neurol 1998;44:134-138.

59 Nielsen AS, Ravid R, Kamphorst W, Jorgensen OS: Apolipoprotein E $\varepsilon 4$ in an autopsy series of various dementing disorders. J Alzheimers Dis 2003;5:119-125.

60 Rascovsky K, Salmon DP, Lipton AM, Leverenz JB, DeCarli C, Jagust WJ, Clark CM, Mendez MF, Tang-Wai DF, Graff-Radford NR, Galasko D: Rate of progression differs in frontotemporal dementia and Alzheimer disease. Neurology 2005;65:397-403.

61 Van Dyck CH, Gelernter J, MacAvoy MG, Avery RA, Criden M, Okereke O, Varma P, Seibyl JP, Hoffer PB: The absence of an apolipoprotein $\mathrm{E} \varepsilon 4$ allele is associated with increased parietal rCBF asymmetry in Alzheimer's disease. Arch Neurol 1998;55:1460-1466.

62 Kokmen E, Ozsarfati Y, Beard CM, O’Brien PC, Rocca WA: Impact of referral bias on clinical and epidemiological studies of Alzheimer's disease. J Clin Epidemiol 1996;49:7983.

63 Watson JS, Matsuyama SS, Dirham PM, Liston EH, La Rue A, Jarvik LF: Relatives' descriptions of changes in symptoms of dementia of the Alzheimer type: a comparison of retrospective and concurrent ratings. Alzheimer Dis Assoc Disord 1987;1:98-102. 